\title{
A method for mixing lights to produce homogeneous illumination*
}

\section{R. CAVONIUS \\ The Psychological Laboratory, Cambridge University. Cambridge $C B 2$ 3EB. England}

A device is described for producing homogeneous illumination. Use is made of internal reflections within a rectangular box.

Burnham (1952) described a method for mixing inhomogeneous light in order to illuminate a viewing screen uniformly. The heart of his apparatus was a block of clear glass or plastic placed between two diffusing screens. The light was mixed by the diffusing screens and by internal reflections from the surfaces of the block. Coren (1970) independently reported a remarkably similar technique, and Cronholm \& Behar (1973) applied Burnham 's device to an ingenious method for generating periodic stimuli. Although the device works well, it is feasible only for small areas (Burnham's was a 1.5-in. square). because large blocks of glass or plastic are heavy and expensive. A more practical solution. to which the author was introduced by C. A. Padgham of the Department of Ophthalmic Optics. The City University. London. is to make use of internal reflections within a rectangular box. the long sides of which are lined with mirrors. Relatively little light is lost in reflections. so this method is considerably more efficient than integrating spheres. The length of the box is not critical, but should be at least twice the diagonal of the end. The mirrors need not be of high quality: we have used shoddy household mirrors to make a large display for classroom demonstrations. It is even possible to line the box with a type of decorating paper that is covered with shiny aluminum foil and to use translucent drafting paper for the diffusing screens. (Aluminum baking foil does not work. It is difficult to obtain a smooth surface with foil, and irregularities result in uneven illumination of the viewing screen.)

The distribution of light at the output of a $10 \times 10 \times$ $300 \mathrm{~cm}$ box with tracing-paper ends was measured with a photomultiplier with a $1-\mathrm{mm}$ aperture. When half the input screen was illuminated. the maximum variation in illumination across the output screen was $4 \%$. When only 17, of the input screen was illuminated, the output variation was $7 \%$. Presumably, milk-glass screens. which are better diffusers. would have reduced this variation still further.

Color mixture can be demonstrated with a simple form of the Ives colorimeter that was described by Riggs

* Supported by the James Mckeen Cattell Fund. I thank Charles Padgham and John Jarvis of the City University, London, for advice in the design and application of this device, and the reviewer for directing $m y$ attention to the striking similarity between Coren's method and the earlier publication of Burnham.
(1964). In this device, the filament image of a slide-projector lamp is focused on three primary-color filters, which are carried on a microscope stage that is mounted vertically. Red and green filters are placed side by side, with the blue filter below (Fig. 1). Thus, horizontal adjustment of the stage changes only the red-green balance: vertical adjustment changes the yellow-blue balance. Most commercial slide projectors contain two condensing lenses. If one is removed. the image of the filament is focused in front of the projector, where the filters are placed. Especially with the concentrated-filament lamps used in many modern projectors, it is advisable to place the filters slightly out of the point of best focus, both to prevent heat damage and to make the adjustment of the stage less critical.

An anomaloscope can be constructed by placing two systems side by side. One contains the color filters described above, and the other carries yellow, transparent. and opaque sections in place of the red, green. and blue filters. Thus, the yellow screen can be adjusted in saturation and brightness to match the red-green mixture on the other screen. The $\mathrm{O}$ is allowed to adjust the red-green ratio. (Automobile speedometer cables can be used to bring the controls to the front of the viewing screen. or the screens can be seen by reflection from a mirror.) The red-green setting that an $O$ makes (his Rayleigh ratio) and the range of red-green settings that he will accept as a satisfactory match to yellow indicate the extent and type of his color deficiency.

Calibration of the system may be difficult unless the user has access to a colorimeter or to a photometer such as the Pritchard. which contains filters that enable the user to measure the tristimulus values of different settings of the microscope stage. If the spectral passbands of the filters are known. the tristimulus values can be calculated. One method for doing this is given by Burnham (1952). A rough calibration can probably be made by comparing the fields with Munsell color chips, for which tristimulus values have been published (Kelly. Gibson. \& Nickerson, 1943). Because the saturation range of the Munsell chips is limited, not all of the possible filter settings can be calibrated by this method.

Selection of filters is not especially critical. although the nearer one gets to the corners of the color diagram, the wider the range of possible matches. We used Ilford Tricolour red. green. and blue: in the U.S.. the Kodak filters recommended by Riggs (1964), red 26, green $61 \mathrm{~N}$. and blue 129. may be more easily obtained. Assuming that one has access to a projector, the most expensive part of the system will probably be the microscope stage. We used Edmund Salvage Co. 


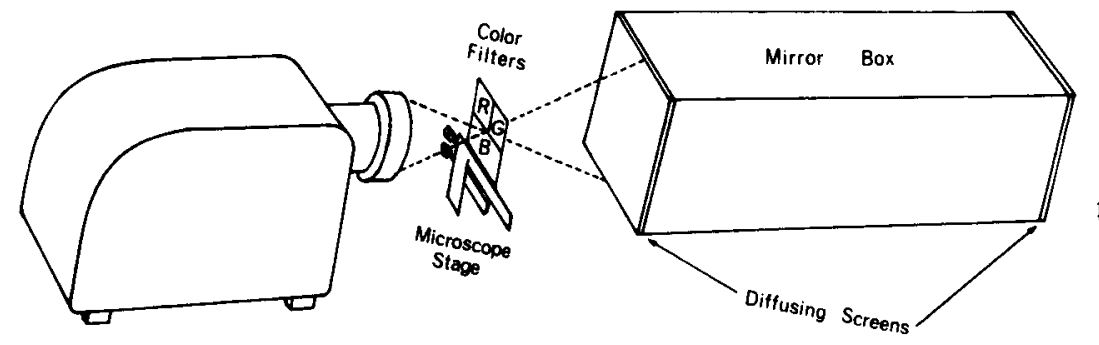

Fig. 1. Schematic view of the light-mixing box, showing its use as a colorimeter.

No. 30058 , but at the latest price of $\$ 44.75$ it may pay the user to cannibalize an old microscope.

\section{REFERENCES}

Burnham, R. W. A colorimeter for research in color perception. American Joumal of Psychology, 1952, 65, 603.

Coren, S. An instrument to produce surface colors of continuously variable brightness. Behavior Research Methods \& Instrumentation, 1970, 2, 263.

Cronholm, J. N., \& Behar, I. A versatile, inexpensive generator of periodic visual stimuli. Vision Research, 1973, 13, 1383.

Kelly, K. L., Gibson, K. S., \& Nickerson, D. Tristimulus specification of the Munsell Book of Color from spectrophotometric measurements. Journal of the Optical Society of America, 1943, 33, 355.

Riggs, L. A. A projection color mixer. American Journal of Psychology, 1964, 77, 129.

(Received for publication May 14, 1973; revision received September $29,1973$. ) 